\title{
Biological and Molecular Diversity of Cucumber green mottle mosaic virus in Spain
}

\author{
Oscar Crespo, Dirk Janssen, Carmen García, and Leticia Ruiz, Instituto Andaluz de Investigacion y Formacion Agraria y Pesquera \\ (IFAPA), 04745 La Mojonera, Almeria, Spain
}

\begin{abstract}
The complete RNA genome from Cucumber green mottle mosaic virus (CGMMV) (Alm08), collected during 2009 in cucumber crops located in Spain, was found to be 6,422 nucleotides long. The nucleotide sequence shared the highest identity with isolates from Russia (GQ495274, GQ495275, FJ848666) as do nucleotide sequences of partial CP and MP genes described in Spain since 2005. All the partial genome sequences including RdRp, CP, and MP from 26 isolates collected from 2013 to 2015 in the southeast of Spain, and from seven isolates of other parts of the world, suggest that they grouped in two major clusters: one cluster (I) included 14

isolates collected between 2013 and 2014, and also reference isolates from France, the Netherlands, and Uzbekistan. A second cluster (II) grouped 12 isolates, which were mostly collected in 2015 together with those from Japan, South Korea, and Canada. For the first time, CGMMV isolates of different geographical origin were found coinfecting the same crop and territory. A host range study revealed that representative isolates of cluster II, but not from cluster I, produced local lesions in Chenopodium amaranticolor. RT-PCR using a common primer pair for CGMMV followed by restriction enzyme analysis with KpnI allowed distinguishing cluster I from II CGMMV isolates.
\end{abstract}

Virus diseases are limiting factors in cucurbit production worldwide. Cucurbit crops can be affected by at least 59 plant viruses (Lecoq and Desbiez 2012). Some of these viruses can cause severe yield losses, spread quickly, and their eradication can be very difficult. Members of the genus Tobamovirus are considered to be extremely stable and can persist for long periods without a living host (Hull 2013; Reingold et al. 2015) and for more than 4 years in desiccated leaves (Mandal et al. 2008). Due to their long persistence, the study of molecular and biological diversity can be very important in establishing a strategy for the control and management of these diseases. Tobamoviruses possess a positive-sense RNA genome and rod-shaped virions. The genome encodes four polypeptides. The 124- to 132-kDa protein contains the methyltransferase and helicase domains, a 181 - to $189-\mathrm{kDa}$ protein that contains the polymerase domain and that is synthesized by readthrough of a leaky stop codon. Both proteins are required for efficient replication. The next ORFs encode a 28- to 31-kDa movement protein (MP), and a 17- to $18-\mathrm{kDa}$ coat protein $(\mathrm{CP})$. Both large proteins are translated directly from the genomic RNA. The MP and CP are expressed from individual 3-coterminal subgenomic RNAs (Adams et al. 2012).

Four tobamoviruses are known to affect cucurbits crops: $\mathrm{Cu}$ cumber green mottle mosaic virus (CGMMV) (Ugaki et al. 1991), Cucumber fruit mottle mosaic virus (CFMMV) (Antignus et al. 2001), Kyuri green mottle mosaic virus (KGMMV) (Yoon et al. 2001), and Zucchini green mottle mosaic virus (ZGMMV) (Ryu et al. 2000; Yoon et al. 2002). From these species, CGMMV is the most widely distributed. It was first reported in the United Kingdom (Ainsworth 1935), and thereafter, additional isolates have been described from Asia (Kim et al. 2003; Ko et al. 2006; Shim et al. 2005; Ugaki et al. 1991; Yoon et al. 2008) and Europe (Antignus et al. 1990; Varveri et al. 2002), which show differences in terms of the susceptibility of the experimental host range and above all in the symptoms that are produced in the host (Mandal et al. 2008). Recently, CGMMV has also been described in North America (Ling and Li 2014; Tian et al. 2014) and Australia (Tesoriero et al. 2016).

Corresponding author: Leticia Ruiz; E-mail: mleticia.ruiz@juntadeandalucia.es

*The $\boldsymbol{e}$-Xtra logo stands for "electronic extra" and indicates that two supplementary figures are available online.

Accepted for publication 20 January 2017.

() 2017 The American Phytopathological Society
Spain is one of the main producers of Cucurbitaceous crops in Europe and one of the top 10 producers in the world of principally watermelon (Citrillus lanatus L.), cucumber (Cucumis sativus L.), melon (Cucumis melo L.), and zucchini (Cucurbita pepo L.) (www.fao.org) with a production of $860,775,750$, and 462 thousand tons, respectively, during 2014 (http://www.mapama.gob.es/ es/). CGMMV was described as CGMMV-Sp in Spain for the first time in the 1990s, affecting cucumber crops grown in plastic greenhouses in Almeria in the southeast of the country (Célix et al. 1996). Subsequently, several outbreaks occurred in that region, affecting mainly cucumber but also watermelon crops. However, since the first description, no biological information on CGMMV in Spain has been available and only two nucleotide sequences of partial CP and MP genes (DQ239488, DQ641259) have been deposited in the GenBank database until now. The virus has a host range limited to cucurbits (Antignus et al. 1990, 2001) and causes symptoms of leaf mottle mosaic, blistering, distortion, and mosaic in fruits. In watermelon, the virus causes a pulp deterioration called blood flesh disease (Mandal et al. 2008) and the fruit loses its marketable value. It is mechanically and seed transmitted, but the virus does not attack the embryo. Like other tobamoviruses, it can survive for a long time in infected crops (Agrios 2004; Reingold et al. 2015).

Here, we have determined the first complete nucleotide sequence and host range of the genomic RNA of a new Spanish isolate of CGMMV (Alm08). In order to evaluate the molecular diversity of CGMMV in the southeast of Spain, partial genome sequences were obtained from isolates that were collected between 2013 and 2015 from watermelon, melon, and cucumber crops grown in greenhouses. Fifteen of these isolates were selected for biological characterization. The coexistence of different Asian and Europeanlike CGMMV isolates in Spain was established, which may have implications for future breeding programs, so we developed a routine diagnostic procedure in order to distinguish between these two groups of viruses.

\section{Materials and Methods}

Virus isolates. Cucumber samples showing symptoms attributed to CGMMV, such as leaf mottle mosaic and mosaic in fruits, were collected from plastic-covered greenhouses located in Almeria during 2009 and tested for CGMMV by ELISA (DSMZ). The samples were also tested for Cucumber mosaic virus and members of the genus Potyvirus by ELISA, and for Cucurbit yellow stunting disorder virus and Cucumber vein yellowing virus by RT-PCR as described by Ruiz et al. (2006), to ensure the absence of one or more of the most 
common viruses affecting cucurbits in the area. One isolate, named Alm08, positive only for CGMMV and further annotated as CGMMV-SP to distinguish from CGMMV-Sp previously described by Célix et al. (1996), was isolated after three passages onto Gomphrena globosa L., propagated in cucumber (cv. Cum laude), and then stored at $-80^{\circ} \mathrm{C}$ until used for full genome determination.

Field surveys were carried out in an $80-\mathrm{km}$ transect in the provinces of Almeria and Granada, which constitute the main protected cucurbit producing areas in Spain. In each of 156 cucumber, 26 watermelon, and 16 melon crops with virus-like symptoms (29 in Granada and 169 in Almeria; 57 samples during 2013, 67 during 2014, and 74 during 2015), at least two samples were collected and analyzed for CGMMV by ELISA and RT-PCR as described above. Samples from 26 greenhouses were positive and were stored in a receptacle containing silica gel until posterior analysis was carried out.

Experimental host range. Five isolates collected in 2013 (CGSPMe2, CG-SPCu3, CG-SPCu5, CG-SPCu6, and CG-SPCu8), three in 2014 (CG-SPCu10, CG-SPCu13, and CG-SPCu14), and seven during 2015 (CG-SPCu16, CG-SPCu18, CG-SPCu20 CG-SPCu24, CG-SPCu28, CG-SPWa21, and CG-SPWa32) produced local lesions in $G$. globosa through which they were isolated after three passages, before being propagated in cucumber. CGMMV-SP was obtained as described above, and the isolate with accession number $0007 \mathrm{~W}$ from South Korea was used as a reference. For the host range study, $0.1 \mathrm{~g}$ of leaves infected with each virus isolate was homogenized in $50 \mathrm{mM}$ sodium phosphate buffer $(\mathrm{pH} 7.0)$ and inoculated mechanically by rubbing the extract onto leaves dusted with carborundum powder. We used 13 indicator plants including G. globosa L, pumpkin (Cucurbita maxima L. cv. Totana), cucumber, melon

Table 1. Primer pair sets used to sequence CGMMV-SP genome

\begin{tabular}{llr}
\hline Name & \multicolumn{1}{c}{ Sequence 5' $\mathbf{3}^{\prime}$} & Size \\
\hline CG227F & CAGAGCACACCAGGCTTGT & 985 \\
CG1211R & TCAGCATCGACAAGCATCCT & \\
CG2099F & AGGCTGTCTTACCGTTGTCG & 968 \\
CG3066R & AGTGACATCTCTAGGACACCT & \\
CG3435 & TGTGGAAAAGGTCGATCAGTC & 1,075 \\
CG4509R & AGTAGTTACATCACCAGACTTCC & \\
CG5160F & CCCTGTCAAGTTGTTGCGTGG & 831 \\
CG5986R & GGACCGTTGAGGAAAGCGTA & \\
\hline
\end{tabular}

(cv. Horacio), watermelon (cv. Crimson sweet), zucchini (cv. Victoria), Chenopodium amaranticolor Coste \& Reyn., C. quinoa Wild., Vigna unguiculata (L.) Walp., Datura stramonium L., Nicotiana tabacum L. cv. Xanthi, N. rustica L., and N. tabacum L. cv. Samsum. The inoculated plants were evaluated for infection and symptoms at 14 days post inoculation (p.i.) and were observed until 4 weeks p.i. The infection was evaluated by ELISA. At least five plants of each species were inoculated and the experiment was repeated twice. All inoculated plants were maintained in an insect-proof greenhouse.

RNA extraction, sequencing, and genome analysis of CGMMV-SP. Total RNA from CGMMV-SP was extracted with Trizol reagent (Invitrogen) according to the manufacturer's instructions. The full-length viral sequence was obtained by RT-PCR with primers designed from previously reported CGMMV sequences in GenBank (AB015146 and NC001801; Table 1) and using primer walking strategy. cDNA clones containing the $5^{\prime}$ and $3^{\prime}$ ends of the genomes were obtained with the SMART RACE cDNA Amplification Kit (Clontech). Each amplified fragment was cloned into pGEM-T Easy vector system (Promega) and sequenced in both directions to check the sequence identity. In both $5^{\prime}$ RACE and 3' RACE, at least two cDNA clones were sequenced in both directions. The complete sequence was assembled using the software BIOEDIT version 7.2.5 (Hall 1999).

Genome analysis of CGMMV. Nucleotide, amino acid, and the $5^{\prime}$ and $3^{\prime}$ untranslated regions (UTR) sequences of CGMMV-SP, of 19 other isolates of CGMMV, and of seven isolates corresponding to KGMMV, ZGMMV, and CFMMV retrieved from the GenBank database were compared. The pairwise percentage of nucleotide and amino acid sequence identity was calculated using the Clustal $\mathrm{W}$ algorithm (Geneious 7.0.6, Biomatters Ltd.). Phylogenetic tree was constructed in the MEGA 6.0 program using the maximum likelihood (ML) method and Tamura-Nei nucleotide substitution model with 1,000 bootstrap replications to assess the robustness of the branches (Tamura et al. 2013).

Detection of potential recombination events in CGMMV-SP, identification of likely parental sequences, and localization of recombination breakpoints were carried out with the Recombination Detection Program 4 (RDP4) using the RDP, GENECONV, Chimaera, MaxChi, BOOTSCAN, and SISCAN methods implemented in the RDP4 program with default settings (Martin et al. 2015). For recombination analysis, the same sequences used in genome analysis were used. The sequences were aligned in MEGA6 software and exported to the RDP4 program for recombination analysis.

Molecular variability of CGMMV isolates. The complete sequence of CGMMV-SP was used for designing three set of

Table 2. Experimental host range and ELISA test results of CGMMV-SP, CGMMV-007W, and 15 isolates collected in Almeria province between 2013 and $2015^{\mathrm{z}}$

\begin{tabular}{|c|c|c|c|c|c|c|c|}
\hline Species & CGMMV-SP & CG-SPMe2 & CG-SPCu3 & CG-SpCu5 & CG-SPCu6 & CG-SPCu8 & CG-SPCu10 \\
\hline \multicolumn{8}{|l|}{ Amaranthaceae } \\
\hline Gomphrena globosa & L RS & L RS & L RS & L RS & L RS & L RS & L RS \\
\hline \multicolumn{8}{|l|}{ Chenopodiaceae } \\
\hline Chenopodium amaranticolor & - & - & - & - & - & - & - \\
\hline Chenopodium quinoa & - & - & - & - & - & - & - \\
\hline \multicolumn{8}{|l|}{ Cucurbitaceae } \\
\hline Cucumis sativus & Mo, G, Bl/+ & Mo, G, Bl/+ & Mo, G, Bl/+ & Mo, G, Bl/+ & Mo, G, Bl/+ & Mo, G, B1/+ & Mo, G, Bl/+ \\
\hline Cucumis melo & Mo, G/+ & Mo, G/+ & Mo, G/+ & Mo, G/+ & Mo, G/+ & Mo, G/+ & Mo, G/+ \\
\hline Citrillus lanatus & Mo, G/+ & Mo, G/+ & Mo, G/+ & Mo, G/+ & Mo, G/+ & Mo, G/+ & Mo, G/+ \\
\hline Cucurbita pepo & $\mathrm{S} /+$ & $\mathrm{S} /+$ & $\mathrm{S} /+$ & $\mathrm{S} /+$ & $\mathrm{S} /+$ & $\mathrm{S} /+$ & $\mathrm{S} /+$ \\
\hline Cucurbita maxima & $\mathrm{CS} /+$ & $\mathrm{CS} /+$ & $\mathrm{CS} /+$ & $\mathrm{CS} /+$ & $\mathrm{CS} /+$ & $\mathrm{CS} /+$ & $\mathrm{CS} /+$ \\
\hline \multicolumn{8}{|l|}{ Fabaceae } \\
\hline Vigna unguiculata & - & - & - & - & - & - & - \\
\hline \multicolumn{8}{|l|}{ Solanaceae } \\
\hline Datura stramonium & - & - & - & - & - & - & - \\
\hline Nicotiana tabacum cv. Xanthi & - & - & - & - & - & - & - \\
\hline Nicotiana rustica & - & - & - & - & - & - & - \\
\hline Nicotiana tabacum cv. Samsun & - & - & - & - & - & - & - \\
\hline
\end{tabular}

${ }^{\mathrm{z}}$ L: local infection; RS: red spots; Mo: mosaic; G: green mottling; Bl: blisters; S: symptomless systemic infection; CS: chlorotic spots; -: immune; +: positive in ELISA test. 
primers that amplified the entire region of the CP: CGM-CPUP 5'GTAAGCGGCATTCTAAACCT- $3^{\prime}$ and CGM-CPLOW 5'-TGCCCAT AAAAACTTCAGCGTCAC- $3^{\prime}$, the partial regions of MP: CGMMPUP 5'-GGCGTTGTGGTTTCTGGTGTATG- ${ }^{\prime}$ and CGM-MPLOW 5'-CTAGGCGTGATCGGATTGTAAGC-3', and the Replicase (Rep): CGM-RepUP 5'-TAGTCGATAATGTAGAGCGTAGG-3' and CGM-RepLOW 5'-CCTCGTCCCTAACAAAAGAAGA-3', which amplified parts of the CGMMV genome of 687, 576, and $909 \mathrm{bp}$, corresponding to nucleotides 5,687 to $6,373,5,212$ to 5,787 , and 3,010 to 3,918 , respectively. Reverse transcription of 26 isolates obtained in the surveys was carried out with a reverse primer using Superscript II (Invitrogen) at $42^{\circ} \mathrm{C}$ for $60 \mathrm{~min}$. Subsequently, DNA fragments were amplified by PCR with Expand High Fidelity PCR System (Roche) with each set of primers and under the following conditions: $95^{\circ} \mathrm{C}$ for $3 \mathrm{~min}, 35$ cycles of denaturation for $20 \mathrm{~s}$ at $95^{\circ} \mathrm{C}$, annealing for $30 \mathrm{~s}$ at $55^{\circ} \mathrm{C}$, and extension for $40 \mathrm{~s}$ at $72^{\circ} \mathrm{C}$, followed by one final extension cycle for $8 \mathrm{~min}$ at $72^{\circ} \mathrm{C}$. PCR products were directly sequenced. In addition, one isolate from Canada, South Korea, Japan, Uzbekistan, France, and two from Holland were also analyzed as described above. Isolates from South Korea and Japan were provided by PVGB (Plant Virus GenBank, http://www.virusbank.org) (accession numbers 0007W and 0102CU, respectively). Phylogenetic relationships between CGMMV-SP, 33 CGMMV isolates plus the isolate CGMMVABCA13-01 (KP772568) retrieved from the GenBank database were inferred for the three genomic regions using the ML method with 1,000 bootstrap replications in MEGA 6.0 (Tamura et al. 2013).

Molecular differentiation of CGMMV isolates. Restriction fragment length polymorphism (RFLP) analysis after RT-PCR was developed to differentiate between CGMMV isolates found in Spain. The nucleotide sequence comparison of the entire CP from all CGMMV isolates found in Spain and the 19 isolates retrieved from the GenBank database showed the existence of conserved differences in the genome sequence between isolates originated from Asia and from Europe. One of the differences suggested that digestion with KpnI restriction enzyme would yield differences after separation of digests in electrophoresis. PCR fragments, primed with CGM-CPUP/CGM-CPLOW as described above, were digested with $K p n I$ (Promega) following the manufacturer's instructions. The restriction patterns were compared after electrophoresis on a $2 \%$ agarose gel.

\section{Results}

Host range study. All isolates analyzed exhibited severe mosaic symptoms in leaves of cucurbits, especially cucumber plants, in which blister symptoms were very frequent (Table 2, Fig. 1). Nine days after inoculation, local red spots emerged in G. globosa. No symptoms and infection were detected in C. amaranticolor when CGMMVSP, CG-SPMe2, CG-SPCu3, CG-SPCu5, CG-SPCu6 CG-SPCu8, CGSPCu10, CG-SPCu13, and CG-SPCu14 were used as the inoculum. However, local lesions were observed in $C$. amaranticolor, 12 days after inoculation with CG-SPCu16, CG-SPCu18, CG-SPCu20, CG-SPCu24, CG-SPCu28, CG-SPWa21, and CG-SPWa32. Between 18 days and 3 weeks after inoculation, interveinal chlorosis, mosaic, and mottling symptoms appeared on cucumber, melon, and watermelon plants, while chlorotic spots were observed on bottle gourd plants. No symptoms occurred in zucchini plants, although the plants tested positive by ELISA. As a consequence, zucchini could be considered an asymptomatic host of Spanish CGMMV isolates analyzed in this work. C. quinoa, $V$. unguiculata, D. stramonium, N. tabacum cv. Xanthi, N. rustica, and N. tabacum cv. Samsum resulted immune with the ELISA tests being negative. The inoculation with CGMMV-007W used as a control showed local infection in C. amaranticolor, but not in G. globosa (Table 2).

Cloning, sequencing and phylogenetic analysis of CGMMVSP. The genome of CGMMV-SP was 6,422 nucleotides long and contained four open reading frames (ORFs) in the positive strand. The first two putative ORFs encoded a $129-\mathrm{kDa}$ (nt 60 to 3,435 ) preread through and a $186-\mathrm{kDa}$ read through (nt 60 to 5,006) protein; ORF 3 encoded the 29-kDa protein involved in cell-to-cell movement (MP; nt 4,993 to 5,787), and ORF 4 the 17.4-kDa coat protein (CP; nt 5,762 to 6,247). The $5^{\prime}$ and $3^{\prime}$ untranslated regions (UTRs) consisted of 59 and 175 nucleotide residues, respectively. The genome organization of CGMMV-SP was therefore identical to that of previously reported isolates such as CGMMV-SH, CGMMV-W, and CGMMV-ABCA13-01 (Li et al. 2015; Ugaki et al. 1991). The sequence data for CGMMV-SP is available under GenBank accession number GQ411361.

The nucleotide sequence comparison using the full genome sequence of CGMMV-SP and 19 worldwide CGMMV isolates showed that it shared the highest identity $(99 \%)$ with three isolates originating from Russia (FJ848666, GQ495275, GQ495274) and the lowest (90\%) with isolates from China and South Korea (Table 3). Virion gene comparison using the same isolates showed similar results. In addition, UTR comparison showed $100 \%$ nucleotide identity between CGMMV-SP and Russian isolates.

The phylogenetic analysis based on the complete genome nucleotide sequences of 19 CGMMV isolates and seven other Tobamovirus species and/or isolates retrieved from the GenBank database revealed that CGMMV-SP formed a cluster with Russian isolates and showed divergent relations with the remaining isolates (Fig. 2).

Table 2. (continued from preceding page)

\begin{tabular}{|c|c|c|c|c|c|c|c|c|c|}
\hline CG-SPCu13 & CG-SPCu14 & CG-SPCu16 & CG-SPCu18 & CG-SPCu20 & CG-SPWa21 & CG-SPCu24 & CG-SPCu28 & CG-SPWa32 & CGMMV-007W \\
\hline L RS & L RS & L RS & L RS & L RS & L RS & L RS & L RS & L RS & - \\
\hline- & - & $\mathrm{L}$ & $\mathrm{L}$ & $\mathrm{L}$ & $\mathrm{L}$ & $\mathrm{L}$ & $\mathrm{L}$ & $\mathrm{L}$ & $\mathrm{L}$ \\
\hline - & - & - & - & - & - & - & - & - & - \\
\hline $\begin{array}{l}\text { Mo, G, Bl/+ } \\
\text { Mo, G/+ } \\
\text { Mo, G/+ } \\
\text { S/+ } \\
\text { CS/+ }\end{array}$ & $\begin{array}{l}\text { Mo, G, Bl/+ } \\
\text { Mo, G/+ } \\
\text { Mo, G/+ } \\
\text { S/+ } \\
\text { CS/+ }\end{array}$ & $\begin{array}{l}\text { Mo, G, Bl/+ } \\
\text { Mo, G/+ } \\
\text { Mo, G/+ } \\
\text { S/+ } \\
\text { CS/+ }\end{array}$ & $\begin{array}{l}\text { Mo, G, Bl/+ } \\
\text { Mo, G/+ } \\
\text { Mo, G/+ } \\
\text { S/+ } \\
\text { CS/+ }\end{array}$ & $\begin{array}{l}\text { Mo, G, Bl/+ } \\
\text { Mo, G/+ } \\
\text { Mo, G/+ } \\
\text { S/+ } \\
\text { CS/+ }\end{array}$ & $\begin{array}{l}\text { Mo, G, Bl/+ } \\
\text { Mo, G/+ } \\
\text { Mo, G/+ } \\
\text { S/+ } \\
\text { CS/+ }\end{array}$ & $\begin{array}{l}\text { Mo, G, Bl/+ } \\
\text { Mo, G/+ } \\
\text { Mo, G/+ } \\
\text { S/+ } \\
\text { CS/+ }\end{array}$ & $\begin{array}{l}\text { Mo, G, Bl/+ } \\
\text { Mo, G/+ } \\
\text { Mo, G/+ } \\
\text { S/+ } \\
\text { CS/+ }\end{array}$ & $\begin{array}{l}\text { Mo, G, Bl/+ } \\
\text { Mo, G/+ } \\
\text { Mo, G/+ } \\
\text { S/+ } \\
\text { CS/+ }\end{array}$ & $\begin{array}{l}\text { Mo, G, Bl/+ } \\
\text { Mo, G/+ } \\
\text { Mo, G/+ } \\
\text { S/+ } \\
\text { CS/+ }\end{array}$ \\
\hline- & - & - & - & - & - & - & - & - & - \\
\hline - & - & - & - & - & - & - & - & - & - \\
\hline - & - & - & - & - & - & - & - & - & - \\
\hline - & - & - & - & - & - & - & - & - & - \\
\hline - & - & - & - & - & - & - & - & - & - \\
\hline
\end{tabular}


No recombination events were detected with the analysis carried out with the RDP4 program. CGMMV-SP is not, then, a recombinant virus; rather, it most probably has a common origin with Russian isolates.
Genetic diversity and phylogenetic analysis of CGMMV in the southeast of Spain. The sequence data of RT-PCR-amplified fragments from three genomic regions (Rep, CP, and MP) in CGMMV-SP, in 26 Spanish isolates collected between 2013 and 2015, and in seven

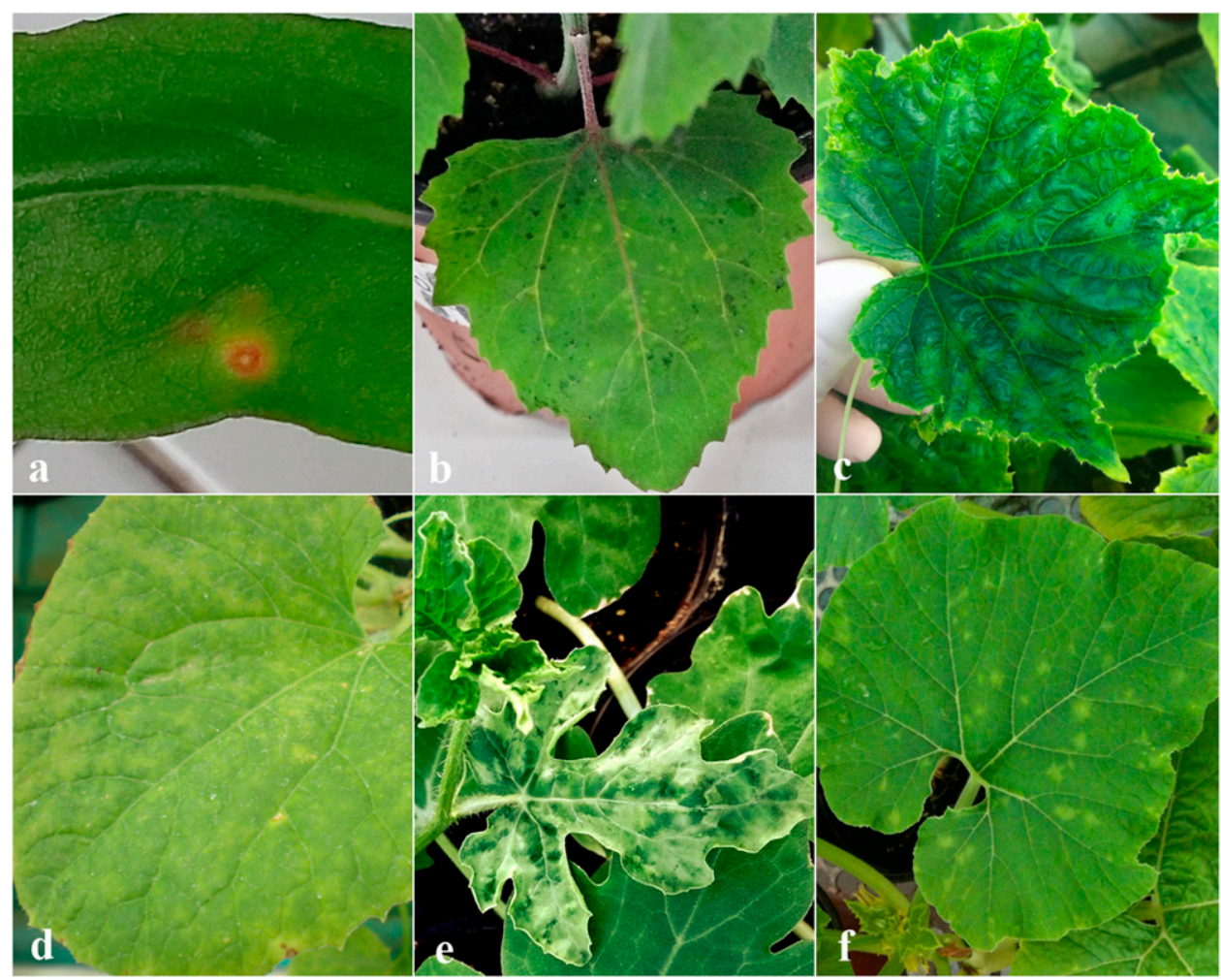

Fig 1. Symptoms in the host range plants inoculated with: a, CGMMV-SP in Gomphrena globosa, b, CGMMV-SPCu16 in Chenopodium amaranticolor, c, CGMMV-SP in cucumber d, CGMMV-SP in melon, e, CGMMV-SPCu16 in watermelon, and f, CGMMV-SP in pumpkin.

Table 3. Percent nucleotide and amino acid identities between CGMMV-SP and selected worldwide CGMMV isolates and other tobamoviruses that affect cucurbit plants

\begin{tabular}{|c|c|c|c|c|c|c|c|c|c|}
\hline Isolate & Host & Accession & Country & Genome & $5^{\prime}$ UTR & Rep & MP & $\mathbf{C P}$ & $3^{\prime}$ UTR \\
\hline CGMMV-MC1 & Cucumber & FJ848666 & Russia & 99.3 & 100 & 99.6 & 99.2 & 96.3 & 100 \\
\hline CGMMV-MC2 & Cucumber & GQ495274 & Russia & 99.3 & 100 & 99.6 & 99.2 & 96.3 & 100 \\
\hline CGMMV-VIROG-43M & Cucumber & GQ495275 & Russia & 99.2 & 100 & 99.4 & 99.2 & 96.3 & 100 \\
\hline CGMMV-Ec & Ecballium elaterium & KF155231 & Israel & 93.2 & 95.0 & 97.9 & 98.1 & 95.7 & 96.6 \\
\hline CGMMV-Ah & Cucumber & KF155232 & Israel & 91.2 & 95.0 & 97.6 & 97.7 & 95.7 & 94.3 \\
\hline CGMMV-Rd & Watermelon & KF155230 & Israel & 90.6 & 91.7 & 97.7 & 97.7 & 95.7 & 94.9 \\
\hline CGMMV-W & Watermelon & AB015146 & Japan & 90.3 & 96.7 & 97.3 & 97.7 & 95.7 & 94.3 \\
\hline CGMMV-Delhi & Bottle gourd & DQ767631 & India & 90.2 & 95.0 & 97.5 & 98.1 & 95.7 & 92.6 \\
\hline CGMMV-XG & Watermelon & KP868654 & China & 90.1 & 98.3 & 97.6 & 98.1 & 95.7 & 93.7 \\
\hline CGMMV-SD Melon & Melon & KJ754197 & China & 90.1 & 88.3 & 97.6 & 97.7 & 95.7 & 93.7 \\
\hline CGMMV-SD Luffa & Luffa cylindrica & KJ754196 & China & 90.1 & 86.7 & 97.6 & 98.1 & 95.7 & 93.7 \\
\hline CGMMV-KOM & Melon & AF417243 & South Korea & 90.1 & 96.7 & 97.5 & 98.1 & 95.7 & 93.1 \\
\hline CGMMV-Watermelon & Nicotiana benthamiana & AB369274 & South Korea & 90.1 & 96.7 & 97.0 & 97.7 & 97.7 & 94.3 \\
\hline CGMMV-ABCA13-01 & Cucumber & KP772568 & Canada & 90.1 & 95.0 & 97.7 & 97.3 & 95.0 & 94.3 \\
\hline CGMMV-TG & Melon & KP868653 & China & 90.0 & 98.3 & 97.5 & 98.1 & 95.7 & 93.7 \\
\hline CGMMV-HG & Bottle gourd & KP868652 & China & 90.0 & 98.3 & 97.3 & 98.1 & 95.7 & 93.7 \\
\hline CGMMV-CCMV_TANG & Pumpkin & HM008919 & China & 90.0 & 96 & 97.4 & 97.7 & 95.7 & 93.1 \\
\hline CGMMV-KW & Watermelon & AF417242 & South Korea & 90.0 & 96.7 & 97.4 & 98.1 & 95.7 & 93.7 \\
\hline CGMMV-SH & Watermelon & NC001801 & Japan & 90.0 & 96.7 & 97.6 & 97.6 & 95.7 & 93.7 \\
\hline CFMMV-Cm & Melon & JN226146 & South Korea & 62.2 & 50.8 & 65.5 & 63.7 & 42.2 & 61.2 \\
\hline CFMMV & Cucumber & NC002633 & Israel & 62.0 & 50.8 & 64.5 & 63.7 & 42.2 & 61.2 \\
\hline KGMMV-C1 & Cucumber & NC003610 & Japan & 61.7 & 59.9 & 64.1 & 59 & 58.3 & 60.8 \\
\hline ZGMMV-K & Zucchini & NC003878 & South Korea & 61.0 & 49.1 & 65.3 & 9.2 & 10.8 & 58.2 \\
\hline ZGMMV-ZT1 & Zucchini & AJ252189 & South Korea & 61.0 & 60.8 & 65.2 & 9.2 & 10.8 & 57.6 \\
\hline KGMMV-Yodo & Cucumber & AB015145 & Japan & 60.8 & 64. & 62.9 & 57.7 & 58.3 & 60.2 \\
\hline KGMMV-YM & Melon & AB 162006 & Indonesia & 60.3 & 55.4 & 59.9 & 57.9 & 58.7 & 60.8 \\
\hline
\end{tabular}


isolates from other parts of the world (Canada, South Korea, Japan, Uzbekistan, France, and Holland), are displayed in Table 4. Identical letters in the table refer to the same sequence accession numbers. Results of phylogenetic analysis of the CP region suggested that the CGMMV isolates grouped in two major clusters. One cluster (I) included isolates from Europe, CGMMV-SP, and Spanish CGMMV isolates collected during 2013 and 2014. On the other hand, a second cluster (II) grouped the majority of Spanish isolates collected in 2015 together with Japanese, South Korean, and Canadian isolates. Isolate CGMMVABCA13-01 retrieved from GenBank also grouped in this second cluster. Only one isolate collected during the present study in 2015 (CG-SPCu27) showed a high identity with CGMMV-SP and the European reference isolates from France, the Netherlands, and Uzbekistan (Fig. 3). Identical results were obtained when the phylogenetic analysis was carried out with the sequence data obtained from the Rep and MP genomic regions (included in supplemental material).

Molecular differentiation of CGMMV. Sequence analysis of all the CGMMV isolates studied in the present paper revealed that the 687-bp RT-PCR amplification product using primers CGM-CPUP and CGM-CPLOW of CGMMV from Asia and similar cluster II isolates found in Spain during 2015 contained a unique KpnI site that was absent in the homologous product from CGMMV-SP, from other isolates collected before 2015, and from isolates from other European countries (cluster I). Restriction digestion with this enzyme yielded two fragments of 514 and $173 \mathrm{bp}$, respectively, in the former amplification product and one 687-bp fragment in the latter (Fig. 4).

\section{Discussion}

The first complete sequence of a CGMMV isolate (Alm08) collected in the southeast of Spain and named CGMMV-SP is presented in this study. Until now, only partial sequences from Western European isolates of CGMMV had been obtained and compared with CGMMV isolates from elsewhere (Boubourakas et al. 2004; Varveri et al. 2002). Comparison of the complete genome sequences from CGMMV-SP with that from 19 CGMMV isolates of different parts of the world, showed the highest nucleotide sequence identity (99\%) with three isolates from Russia (Table 3). The subsequent phylogenetic analysis of these complete genome sequences yielded separate clusters: a first cluster grouped all the Asian isolates, a second one grouped CGMMV-SP and the Russian isolates, and a distinct third cluster formed by the genome sequences from other nonCGMMV tobamoviruses that infect cucurbits (Fig. 2). This genetic relationship may suggest that CGMMV-SP, introduced in the southeast of Spain more than two decades ago, could have a common origin with the Russian isolates.

In their first report of CGMMV in Spain, Célix et al. (1996) described zucchini plants as immune to CGMMV-Sp but no molecular

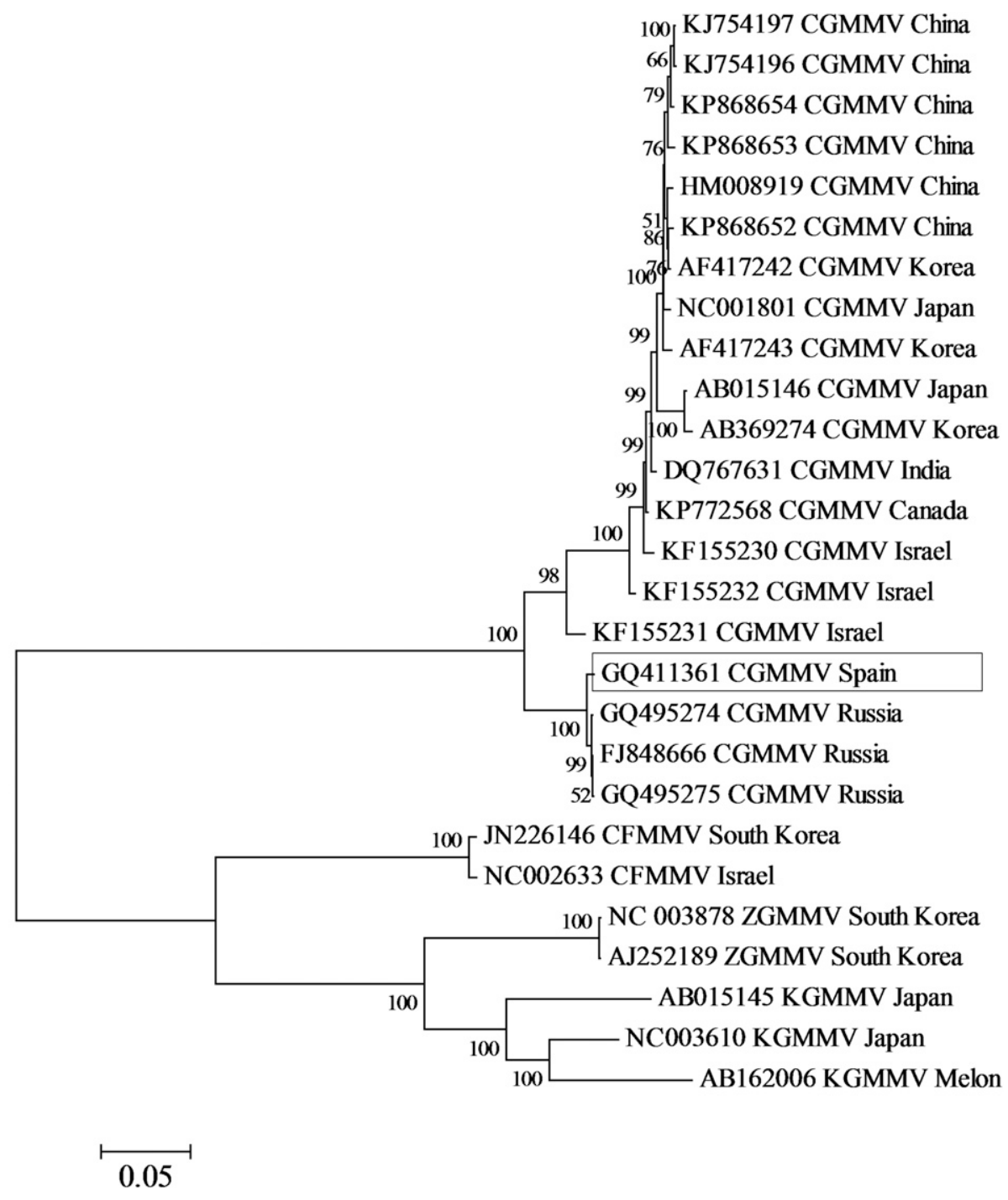

Fig 2. Phylogenetic analysis of the complete genome of CGMMV-SP (framed), selected GenBank CGMMV isolates and other Tobamovirus species that infect Cucurbitaceae. The trees were constructed based on the maximum likelihood method with a 1,000-replicate bootstrap search. The bootstrap values are indicated at the branch points. The bar represents 0.05 nt substitutions per site. 
diagnostic (ELISA or RT-PCR) was done at that time. In the present study, inoculated plants produced no symptoms but had positive results after ELISA, so zucchini behaved as an asymptomatic host during the host range study (Table 2), which is in agreement with the symptoms induced by other CGMMV isolates like CGMMV-Is and that are cataloged as faint yellow spots or simply absent (Antignus et al. 2001).

The phylogenetic analysis of sequences from the $\mathrm{CP}$ region of CGMMV-SP, of isolates collected in greenhouses from the southeast of Spain, and of seven reference isolates from different countries, showed that 13 Spanish isolates collected during 2013 and 2014 grouped together with CGMMV-SP and European isolates (from France, Holland, and Uzbekistan) (cluster I). However, only one isolate collected during 2015 clustered together with CGGMV-SP, whereas 12 remaining isolates from that same year grouped together with reference isolates from Canada, South Korea, and Japan (cluster II) (Fig. 3). The coexistence of different CGMMVs in the southeast of Spain was also suggested by the host range study of representative isolates. Most of the CGMMV isolates previously described such as CGMMV-W (Kim et al. 2000), CGMMV-Is (Antignus et al. 2001), CGMMV-KW (Kim et al. 2003), CGMMV-NW-1, CGMMV-NW-2, and CGMMV-KC1-2 (Yoon et al. 2008), and cucurbit-infecting tobamoviruses like CFMMV and KGMMV-Y (Antignus et al. 2001; Tan et al. 2000), infect C. amaranticolor inducing local lesions or chlorotic spots. In the present study, this plant species showed local lesions following inoculation with CG-SPCu16, CG-SPCu18, CG-SPCu20 CG-SPCu24, CG-SPCu28, CG-SPWa21, and CGSPWa32, collected during the 2015 survey, as well as with the reference isolate from watermelon CGMMV-007W, from South Korea
(Yoon et al. 2008). In agreement with Célix et al. (1996), C. amaranticolor, however, was a nonhost to CGMMV-SP, isolated in 2008, and CG-SPMe2, CG-SPCu3, CG-SPCu5, CG-SPCu6 CG-SPCu8, CG-SPCu10, CG-SPCu13, and CG-SPCu14, isolated in 2013 and 2014 (Table 2), which is similar to what is described for the Korean oriental melon isolate, CGMMV-KOM (Kim et al. 2003), or the isolate CGMMV-CGR collected in Greece (Boubourakas et al. 2004).

The expression of symptoms produced in C. amaranticolor after mechanical inoculation can be used to differentiate between CGMMV-SP-like isolates (cluster I) and Spanish CGMMV isolates related to those from Asian countries (cluster II). This is normally quite a time-consuming procedure, but from CGMMV isolate sequence analysis, a faster method to differentiate the two clusters became evident. Restriction digestion with $K p n I$ of RT-PCR amplification products using primers CGM-CPUP/CGM-CPLOW yielded two fragments in isolates from cluster II isolates, but not in those from cluster I (Fig. 4). This protocol has been extensively used in our routine analysis with field isolates showing CGMMV symptoms, and because of the low variation rate of the viral genomes of tobamoviruses (García-Arenal et al. 2001), we expect the test to remain robust, reliable, and suitable for characterizing new CGMMV isolates.

During the field survey of 2015, we identified CGMMV in mini-cucumber crops, a novel variety in Spain that is increasingly produced. Recently, similar crops have been associated with the introduction of Asian-like CGMMV isolates in Canada (Ling and $\mathrm{Li}$ 2014). A representative isolate, CGMMV-ABCA13-01, has been sequenced and we found this isolate to group in cluster II together with the Asian-like isolates we found during the 2015 survey (Li et al.

Table 4. GenBank accession number and description of CGMMV isolates collected during field surveys in Granada and Almeria provinces. Some GenBank accession numbers display a lowercase letter situated on the right of the code. The sequences with the same lowercase letter are identical (sequence $\mathrm{KX} 353560 \mathrm{q}$ in the CP column from isolate $007 \mathrm{~W}$ is identical to sequence obtained from 0102CU isolate).

\begin{tabular}{|c|c|c|c|c|c|c|}
\hline Isolate & Date & Host & Location & Rep & MP & CP \\
\hline CGMMV-SP & 2009 & Cucumber & Almeria, Spain & GQ411361a & GQ411361f & GQ411361 \\
\hline CG-SPCu1 & 2013 & Cucumber & Almeria, Spain & $\mathrm{a}$ & $f$ & KX353553k \\
\hline CG-SPMe2 & 2013 & Melon & Almeria, Spain & KX353576 & $f$ & $\mathrm{k}$ \\
\hline CG-SPCu3 & 2013 & Watermelon & Almeria, Spain & $\mathrm{a}$ & $\mathrm{f}$ & $\mathrm{k}$ \\
\hline CG-SPCu4 & 2013 & Cucumber & Almeria, Spain & $\mathrm{a}$ & $f$ & $\mathrm{k}$ \\
\hline CG-SPCu5 & 2013 & Cucumber & Almeria, Spain & KX353577 & KX353564g & $\mathrm{k}$ \\
\hline CG-SPCu6 & 2013 & Cucumber & Almeria, Spain & KX353578b & KX353565h & KX353554m \\
\hline CG-SPCu 7 & 2013 & Cucumber & Almeria, Spain & $\mathrm{b}$ & $\mathrm{h}$ & $\mathrm{m}$ \\
\hline CG-SPCu8 & 2013 & Cucumber & Almeria, Spain & $\mathrm{b}$ & $\mathrm{h}$ & $\mathrm{m}$ \\
\hline CG-SPCu9 & 2013 & Cucumber & Almeria, Spain & $\mathrm{a}$ & g & $\mathrm{k}$ \\
\hline CG-SPCu10 & 2014 & Cucumber & Almeria, Spain & $\mathrm{a}$ & $\mathrm{f}$ & $\mathrm{k}$ \\
\hline CG-SPCu12 & 2014 & Cucumber & Almeria, Spain & $\mathrm{a}$ & $\mathrm{f}$ & $\mathrm{k}$ \\
\hline CG-SPCu 13 & 2014 & Cucumber & Almeria, Spain & a & $\mathrm{f}$ & $\mathrm{k}$ \\
\hline CG-SPCu14 & 2014 & Cucumber & Almeria, Spain & $\mathrm{a}$ & f & $\mathrm{k}$ \\
\hline CG-SPCu16 & 2015 & Cucumber & Almeria, Spain & KX353579c & KX353566i & KX353555n \\
\hline CG-SPCu18 & 2015 & Cucumber & Almeria, Spain & c & $\mathrm{i}$ & $\mathrm{n}$ \\
\hline CG-SPCu20 & 2015 & Cucumber & Almeria, Spain & $\mathrm{c}$ & KX353567j & KX353556o \\
\hline CG-SPWa21 & 2015 & Watermelon & Almeria, Spain & KX353580 & KX3535681 & KX353557p \\
\hline CG-SPCu22 & 2015 & Cucumber & Almeria, Spain & $\mathrm{c}$ & $\mathrm{j}$ & o \\
\hline CG-SPCu23 & 2015 & Cucumber & Almeria, Spain & $\mathrm{c}$ & $\mathrm{j}$ & o \\
\hline CG-SPCu24 & 2015 & Cucumber & Almeria, Spain & $\mathrm{c}$ & $\mathrm{j}$ & o \\
\hline CG-SPCu25 & 2015 & Cucumber & Almeria, Spain & $\mathrm{c}$ & $\mathrm{j}$ & o \\
\hline CG-SPCu27 & 2015 & Cucumber & Almeria, Spain & $\mathrm{a}$ & $\mathrm{f}$ & $\mathrm{k}$ \\
\hline CG-SPCu 28 & 2015 & Cucumber & Almeria, Spain & c & $\mathrm{i}$ & o \\
\hline CG-SPCu30 & 2015 & Cucumber & Granada, Spain & c & $\mathrm{j}$ & o \\
\hline CG-SPWa31 & 2015 & Watermelon & Almeria, Spain & KX353581d & 1 & $\mathrm{p}$ \\
\hline CG-SPWa32 & 2015 & Watermelon & Almeria, Spain & d & 1 & $\mathrm{p}$ \\
\hline M191 & 2007 & Cucumber & Canada & KX353582 & KX353570 & KX353559 \\
\hline $007 \mathrm{~W}$ & NA & Watermelon & South Korea & KX353583e & KX353571 & KX353560q \\
\hline 0102CU & NA & Cucumber & Japan & $\mathrm{e}$ & KX353572 & $\mathrm{q}$ \\
\hline L133 & 2006 & Cucumber & Uzbekistan & KX353584 & KX353573 & KX353561 \\
\hline N170 & 2008 & Cucumber & France & $\mathrm{a}$ & KX353574 & $\mathrm{k}$ \\
\hline M94 & 2007 & Cucumber & Netherlands & KX353585 & KX353575 & KX353562 \\
\hline S1234 & 2010 & Cucumber & Netherlands & $\mathrm{a}$ & $\mathrm{f}$ & KX353563 \\
\hline
\end{tabular}


2015). Therefore, we hypothesize that the recent outbreaks of CGMMV isolates that were genetically and biologically different from CGMMV-SP have occurred due to a contaminated cucumber seed batch produced in Asia as has been reported recently from other geographic regions (Li et al. 2015).

Even though various studies on tobamoviruses have revealed that populations remain rather stable (Fraile et al. 1996; Hull 2013), other authors showed a different picture with rapid evolutionary dynamics in the genus Tobamovirus (Pagán et al. 2010) and there is even some evidence for recombination under natural conditions between species of genus Tobamovirus (Chavan and Pearson 2016; Salem et al. 2016). The presence of different isolates in the same territory, as we found in the present study, could generate new variants showing novel genetic features. This might change the genetic structure of the viral population and be crucial to efficient and stable control strategies (Syller 2012).

To our knowledge and probably due to commercial exchanges of CGMMV infected plants and/or seeds, this is the first time that CGMMV isolates of different geographical origin were found in the same territory. The implications in future breeding programs of virus resistant cultivars will have to take this into account.

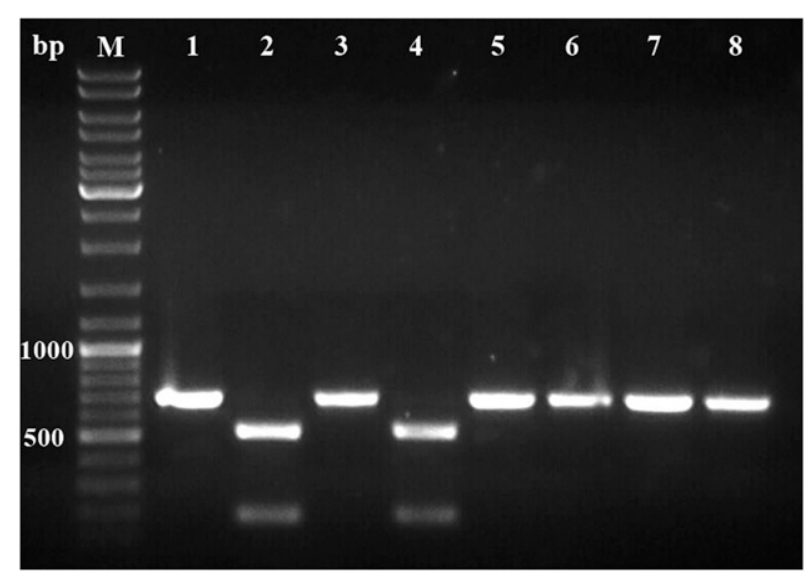

Fig 4. RFLP analysis with Kpnl of RT-PCR products generated by primers CGM-CPUP/ CGM-CPLOW. Lane M: molecular weight. Lanes 1, 3, 5, and 7: uncut amplification products of CGMMV-SP16, CGMMV-SP21, CGMMV-SP, and CGMMV-SP14, respectively. Lanes 2, 4, 6, and 8: cut amplification products of CGMMV-SP16, CGMMV-SP21, CGMMV-SP, and CGMMV-SP14.

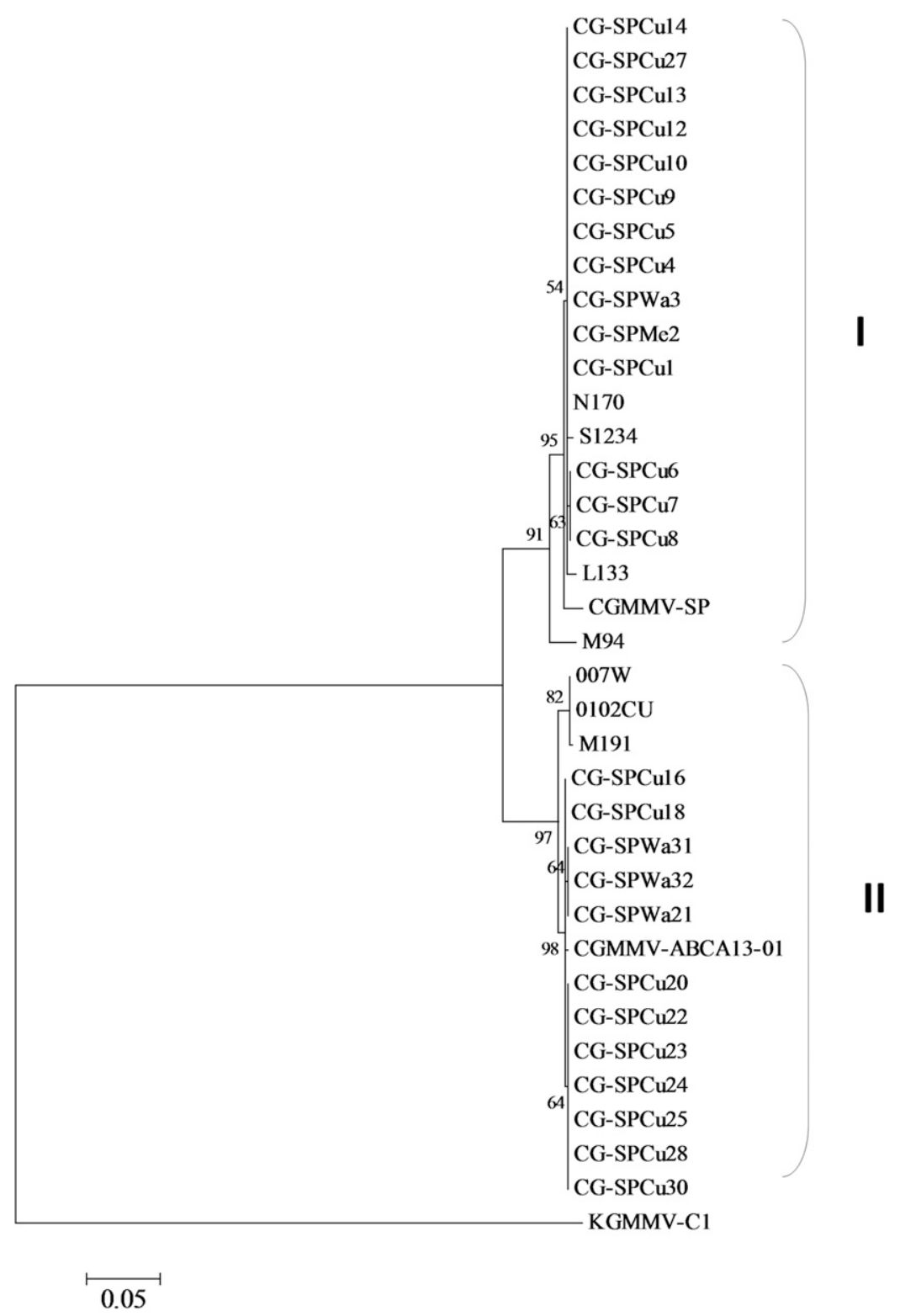

Fig 3. Phylogenetic analysis of partial sequences of the entire coat protein using the maximum likelihood method with a 1,000-replicate bootstrap search. KGMMV-C1 (NC 003610) was used as outgroup. Group I, European isolates, CGMMV-SP, and Spanish isolates collected during 2013 and 2014. Group II, the majority of Spanish isolates collected in 2015 together with Asian and Canadian isolates. See Table 4 for origin and location of the isolates. The bootstrap values are indicated at the branch points. The bar represents $0.05 \mathrm{nt}$ substitutions per site. 


\section{Acknowledgments}

The authors would like to thank M. A. Elorrieta from LabColor (Coexphal) for help during the field surveys. Leticia Ruiz was supported by a research contract of IFAPA and Programa Operativo FSE de Andalucía 2007-2013 "Andalucía se mueve con Europa". Oscar Crespo was supported by the Instituto Nacional de Investigación y Tecnología Agraria y Alimentaria (INIA) and the European Social Fund. This work was supported by RTA2012-00003-00-00 from INIA and by FEDER. The authors are thankful to Plant Virus GenBank (PVGB) of Seoul Women's University of Korea for providing the isolates $0007 \mathrm{~W}$ and $0102 \mathrm{CU}$. We also want to thank Antonia Belmonte and Carmen Robles for technical assistance.

\section{Literature Cited}

Adams, M. J., Heinze, C., Jackson, A. O., Kreuze, J. F., Macfarlane, S. A., and Torrance, L. 2012. Virgaviridae. Pages 1139-1161 in: Virus taxonomy: ninth report of the International Committee on Taxonomy of Viruses. Elsevier/ Academic Press, London.

Agrios, G. 2004. Plant Pathology, 5th Ed. Academic Pres, San Diego, CA.

Ainsworth, G. C. 1935. Mosaic disease of cucumber. Ann. Appl. Biol. 22:55-67.

Antignus, Y., Pearlsman, M., Ben-Yoseph, R., and Cohen, S. 1990. Occurrence of a variant of Cucumber green mottle mosaic virus in Israel. Phytoparasitica 18: 50-56.

Antignus, Y., Wang, Y., Pearlsman, M., Lachman, O., Lavi, N., and Gal-On, A. 2001. Biological and molecular characterization of a new cucurbit-infecting tobamovirus. Phytopathology 91:565-571.

Boubourakas, I. N., Hatziloukas, E., Antignus, Y., and Katis, N. I. 2004. Etiology of leaf chlorosis and deterioration of the fruit interior of watermelon plants. J. Phytopathol. 152:580-588.

Célix, A., Luis-Arteaga, M., and Rodriguez-Cerezo, E. 1996. First report of Cucumber green mottle mosaic tobamovirus infecting greenhouse-grown cucumber in Spain. Plant Dis. 80:1303.

Chavan, R. R., and Pearson, M. N. 2016. Molecular characterisation of a novel recombinant Ribgrass mosaic virus strain FSHS. Virol. J. 13:29.

Fraile, A., Malpica, J. M., Aranda, M. A., Rodnguez-Cerezo, E., and Garcia-Arenal, F. 1996. Genetic diversity in Tobacco mild green mosaic tobamovirus infecting the wild plant Nicotiana glauca. Virology 223:148-55.

García-Arenal, F., Fraile, A., and Malpica, J. M. 2001. Variability and genetic structure of plant virus populations. Annu. Rev. Phytopathol. 39:157-186.

Hall, T. A. 1999. BioEdit: a user friendly biological sequence alignment editor and analysis program for Windows 95/98/NT. Nucl. Ac. Sympos Ser. 41:95-98.

Hull, R. 2013. Plant Virology, 5th Ed. Academic Press, San Diego, CA.

Kim, J. S., Cho, J. D., Choi, H. S., and Kim, K. S. 2000. Ultrastructural aspects of the mixed infections of Watermelon mosaic potyvirus and Cucumber green mottle mosaic tobamovirus isolated from watermelon. Plant Pathol. J. 16:211-215.

Kim, S. M., Lee, J. M., Yim, K. O., Oh, M. H., Park, J. W., and Kim, K. H. 2003. Nucleotide sequences of two Korean isolates of Cucumber green mottle mosaic virus. Mol. Cells 16:407-412.

Ko, S. J., Lee, Y. H., Cha, K. H., Lee, S. H., Choi, H. S., Choi, Y. S., Lim, G. C., and Kim, K. H. 2006. Incidence and distribution of virus disease on cucumber in Jeonnam province during 1999-2002. Plant Pathol. J. 22:147-151.

Lecoq, H., and Desbiez, C. 2012. Viruses of cucurbit crops in the Mediterranean region: An ever-changing picture. Adv. Virus Res. 84:67-126.

Li, R., Zheng, Y., Fei, Z., and Ling, K. S. 2015. First complete genome sequence of an emerging Cucumber green mottle mosaic virus isolate in North America. Genome Announc. 3:e00452-15.

Ling, K. S., and Li, R. 2014. First report of Cucumber green mottle mosaic virus in Canada. Plant Dis. 98:701.
Mandal, S., Mandal, B., and Varma, A. 2008. Properties, diagnosis and management of Cucumber green mottle mosaic virus. Plant Viruses 2:25-34.

Martin, D., Murrell, B., Golden, M., Khoosal, A., and Muhire, B. 2015. RDP4: Detection and analysis of recombination patterns in virus genomes. Virus Evol. 1:vev003.

Pagán, I., Firth, C., and Holmes, E. C. 2010. Phylogenetic analysis reveals rapid evolutionary dynamics in the plant RNA virus genus Tobamovirus. J. Mol. Evol. 71:298-307.

Reingold, V., Lachman, O., Belausov, E., Koren, A., Mor, N., and Dombrovsky, A. 2015. Epidemiological study of Cucumber green mottle mosaic virus in greenhouses enables reduction of disease damage in cucurbit production. Ann. Appl. Biol. 168:245-255.

Ruiz, L., Janssen, D., Martín, G., Velasco, L., Segundo, E., and Cuadrado, I. M. 2006. Analysis of the temporal and spatial disease progress of Bemisia tabaci-transmitted Cucurbit yellow stunting disorder virus and Cucumber vein yellowing virus in cucumber. Plant Pathol. 55:264-275.

Ryu, K. H., Min, B. E., Choi, G. S., Choi, S. H., Kown, S. B., Noh, G. M., Yoon, J. Y., Choi, Y. M., Jang, S. H., Lee, G. P., Cho, K. H., and Park, W. M. 2000. Zucchini green mottle mosaic virus is a new tobamovirus; comparison of its coat protein gene with that of Kyuri green mottle mosaic virus. Arch. Virol. 145:2325-2333.

Salem, N., Mansour, A., Ciuffo, M., Falk, B. W., and Turina, M. 2016. A new tobamovirus infecting tomato crops in Jordan. Arch. Virol. 161:503-506.

Shim, C. K., Han, K. S., Lee, J. H., Bae, D. W., Kim, D. K., and Kim, H. K. 2005 Isolation and characterization of watermelon isolate of Cucumber green mottle mosaic virus (CGMMV-HY1) from watermelon plants with severe mottle mosaic symptoms. Plant Pathol. J. 21:167-171.

Syller, J. 2012. Facilitative and antagonistic interactions between plant viruses in mixed infections. Mol. Plant Pathol. 13:204-216.

Tamura, K., Stecher, G., Peterson, D., Filipski, A., and Kumar, S. 2013. MEGA6: Molecular Evolutionary Genetics Analysis Version 6.0. Mol. Biol. Evol. 30: 2725-2729.

Tan, S. H., Nishiguchi, M., Murata, M., and Motoyoshi, F. 2000. The genome structure of Kyuri green mottle mosaic tobamovirus and its comparison with that of Cucumber green mottle mosaic tobamovirus. Arch. Virol. 145:1067-1079.

Tesoriero, L. A., Chambers, G., Srivastava, M., Smith, S., Conde, B., and TranNguyen, L. T. T. 2016. First report of Cucumber green mottle mosaic virus in Australia. Australas. Plant Dis. Notes 11:1.

Tian, T., Posis, K., Maroon-Lango, C. J., Mavrodieva, V., Haymes, S., Pitman, T. L., and Falk, B. W. 2014. First report of Cucumber green mottle mosaic virus on melon in the United States. Plant Dis. 98:1163.

Ugaki, M., Tomiyama, M., Kakutani, T., Hidaka, S., Kiguchi, T., Nagata, R., and Nishiguchi, M. 1991. The complete nucleotide sequence of Cucumber green mottle mosaic virus (SH strain) genomic RNA. J. Gen. Virol. 72:1487-1495.

Varveri, C., Vassilakos, N., and Bem, E. I. 2002. Characterization and detection of Cucumber green mottle mosaic virus in Greece. Phytoparasitica 30:493-501.

Yoon, J. Y., Choi, G. S., Choi, S. K., Hong, J. S., Choi, J. K., Kim, W., Lee, G. P., and Ryu, K. H. 2008. Molecular and biological diversities of Cucumber green mottle mosaic virus from cucurbitaceous crops in Korea. J. Phytopathol. 156: 408-412.

Yoon, J. Y., Min, B. E., Choi, J. K., and Ryu, K. H. 2002. Genome structure and production of biologically active in vitro transcripts of cucurbit- infecting Zucchini green mottle mosaic virus. Phytopathology 92:156-163.

Yoon, J. Y., Min, B. E., Choi, S. H., and Ryu, K. H. 2001. Completion of nucleotide sequence and generation of highly infectious transcripts to cucurbits from full-length cDNA clone of Kyuri green mottle mosaic virus. Arch. Virol. 146:2085-2096. 